\title{
Recruitment variability in Baltic Sea sprat (Sprattus sprattus) is tightly coupled to temperature and transport patterns affecting the larval and early juvenile stages
}

\author{
H. Baumann, H.-H. Hinrichsen, C. Möllmann, F.W. Köster, A.M. Malzahn, and \\ A. Temming
}

\begin{abstract}
Recruitment patterns of Baltic Sea sprat (Sprattus sprattus) were correlated to time series of (i) month- and depth-specific temperature conditions and (ii) larval drift patterns inferred from long-term Lagrangian particle simulations. From the latter, we derived an index that likely reflected the variable degree of annual larval transport from the central, deep spawning basins to the shallow coastal areas of the Baltic Sea. The drift index was significantly $(P<$ 0.001 ) correlated to sprat recruitment success and explained, together with sprat spawning stock biomass, $82 \%$ of the overall variability between 1979 and 2003. Years of strong larval displacement towards southern and eastern Baltic coasts corresponded to relative recruitment failure, while years of retention within the deep basins were associated with relative recruitment success. The strongest correlation between temperature and recruitment occurred during August in surface waters, explaining $73 \%$ of the overall variability. Together, the two approaches advocate that new year classes of Baltic sprat are predominantly composed of individuals born late in the season and are determined in strength mainly by processes acting during the late larval and early juvenile stages. However, prior to be included in recruitment predictions, the biological mechanisms underlying these strong correlations may need to be better resolved.
\end{abstract}

Résumé : Nous avons mis en corrélation les patrons de recrutement du sprat (Sprattus sprattus) de la Baltique avec des séries chronologiques ( $i$ ) de conditions de température en fonction du mois et de la profondeur et (ii) de patrons de dérive des larves obtenus à partir de simulations de Lagrange à long terme de particules. D'après ces simulations, nous avons élaboré un indice qui représente vraisemblablement le degré variable de transport annuel des larves depuis les bassins de fraye centraux et profonds vers les zones côtières peu profondes de la Baltique. L'indice de dérive est en corrélation significative $(P<0,001)$ avec le succès du recrutement du sprat; combiné à la biomasse du stock reproducteur du sprat, il explique $82 \%$ de la variabilité globale entre 1979 et 2003. Les années de fort déplacement des larves vers les côtes du sud et de l'est de la Baltique correspondent à des insuccès relatifs du recrutement, alors que les années de rétention dans les bassins profonds sont associées à un succès relatif du recrutement. La corrélation la plus forte entre la température et le recrutement s'observe en août dans les eaux superficielles, ce qui explique $73 \%$ de la variabilité globale. Ensemble, les deux approches indiquent que les nouvelles classes d'âge annuelles des sprats de la Baltique se composent principalement d'individus nés tard dans la saison et que la force des classes est déterminée par des processus qui agissent à la fin de la vie larvaire et durant les stades juvéniles. Cependant, il faut mieux élucider les mécanismes sous-jacents à ces fortes corrélations avant de les inclure dans les prédictions du recrutement.

[Traduit par la Rédaction]

Received 11 October 2005. Accepted 1 June 2006. Published on the NRC Research Press Web site at http://cjfas.nrc.ca on 15 September 2006.

J18927

H. Baumann ${ }^{1}$ and A. Temming. Institute for Marine Ecosystems and Fisheries Science, Olbersweg 24, 22767, Hamburg, Germany.

H.-H. Hinrichsen. Leibniz Institute of Marine Science, Düsternbrooker Weg 20, 24105, Kiel, Germany.

C. Möllmann and F.W. Köster. Danish Institute for Fisheries Research, Charlottenlund Castle, DK-2920, Charlottenlund, Denmark.

A.M. Malzahn. Alfred Wegener Institute for Polar and Marine Research, Biologische Anstalt Helgoland, Ostkaje 1118, 27498 Helgoland, Germany.

${ }^{1}$ Corresponding author (e-mail: hannes.baumann@uni-hamburg.de). 


\section{Introduction}

Explaining and predicting recruitment variability are perennial goals in fisheries science (Sissenwine 1984). In sprat, Sprattus sprattus, currently the most abundant, commercially exploited fish species in the Baltic Sea, recruitment variability has increased considerably at the beginning of the 1990s (ICES 2005a), thereby coinciding with other profound changes in the Baltic ecosystem that affected all trophic levels (Alheit et al. 2005).

Previous studies have found significant but weak correlations between recruitment strength and $(i)$ spawning stock biomass (SSB) and (ii) temperature conditions experienced during the egg and early larval stages of Baltic Sea sprat (Köster et al. 2003; MacKenzie and Köster 2004). However, Köster et al. (2003) noted that estimates of egg and larval abundance are generally well correlated, whereas larval production poorly predicts recruitment levels. It has been argued, thus, that year-class strength in Baltic Sea sprat may rather be determined by environmental influences during the late larval and early juvenile stages (Voss et al. 2005). Thus, to improve current sprat recruitment models, potential environmental effects may need to be considered throughout all pre-recruit life stages.

Feeding sprat larvae predominantly occur in surface waters (Voss et al. 2003), where variable, wind-driven circulation patterns may transport them either to suitable or unsuitable nursery areas (Sinclair 1988). Previously, we followed this rationale by using a hydrodynamic circulation model in combination with Lagrangian particle tracking to simulate 23 years of larval sprat drift patterns (Baumann et al. 2004). Our retention index, defined as the annual proportion of drifters collected within predefined rectangles in and outside of the Bornholm Basin, a major sprat spawning area (Köster et al. 2001), was significantly related to the number of age- 0 sprat recruits in the central Baltic. The relationship suggested that retention within the deep basin would be beneficial for recruitment, while dispersion and transport to southeastern Baltic shores would lead to relative recruitment failure. Shortcomings of the previous approach were that the index $(i)$ did not explain the full recruitment time series but only the most recent 12 years, (ii) was restricted to sprat from the Bornholm Basin, and (iii) relied on the definition of arbitrary rectangles in the model domain (Baumann et al. 2004).

Here we present an improved drift index to explain sprat recruitment variability within the entire Baltic Sea and over the whole, extended time series of 25 years (1979-2003). The index was again based on hydrodynamic modelling in conjunction with Lagrangian particle simulations, but instead of final horizontal drifter positions (previous approach), we now integrated the entire drift period by considering the average water depth across all daily particle positions to be a proxy of larval transport from the deep spawning basins to the coast. The underlying rationale was that years of predominant larval retention or coastal transport should result in anomalously deep or shallow particle distributions, respectively.

In a second line of investigation, we evaluated the relationship between recruitment variability and month- and depth-specific temperature conditions based on 30 years of observations. In contrast with previous studies, our approach did not make any a priori assumptions regarding the time and the water depth (and thus the life stage affected) of such potential temperature-recruitment correlations, thereby encompassing possible effects prior, during, and after the main spawning season of Baltic Sea sprat.

\section{Materials and methods}

\section{Hydrodynamic circulation model}

A comprehensive description of the hydrodynamic model and the Lagrangian particle-tracking technique has recently been published by Hinrichsen et al. (2005). Briefly, the three-dimensional, baroclinic circulation model of the Baltic Sea (Lehmann 1995; Lehmann and Hinrichsen 2000) is an adaptation of the free surface Bryan-Cox-Semtner model (Killworth et al. 1991), with a model domain that encompasses the entire Baltic Sea, including the Gulf of Bothnia, Gulf of Riga, the Belt Seas, Kattegat, and the Skagerrak, with a realistic bottom topography. The horizontal resolution is $5 \mathrm{~km}$, and 60 vertical levels are specified with a thickness chosen to best represent the different sill depths in the Baltic Sea. The model is forced by atmospheric data provided on a $1^{\circ} \times 1^{\circ}$ grid (i.e., geostrophic wind, $2 \mathrm{~m}$ air temperature, $2 \mathrm{~m}$ relative humidity, surface pressure, cloudiness, and precipitation; Swedish Meteorological and Hydrological Institute, Norrköping) and river runoff taken from a mean runoff database (Bergstrøm and Carlsson 1994). The model was run for a time series of 25 years (1979-2003). Threedimensional velocity fields extracted from the circulation model were used to predict the trajectories of passive Lagrangian drifters using a 4th order Runge-Kutta scheme (Hinrichsen et al. 1997), which allowed particles to be tracked independently from the resolution of the hydrodynamic circulation model. Along each particle's drift path, corresponding bottom depths (i.e., the water depth at the current position of each particle) were initially stored in $6 \mathrm{~h}$ intervals, but later averaged to obtain daily estimates.

\section{Particle releases and indices}

Initial horizontal drifter positions were based on average sprat egg distributions in the Baltic Sea (Köster 1994; A. Makarchouk, Latvian Fisheries Research Institute, Daugavgrivas St. 8, Riga, LV-1007, Latvia, unpublished data), assumed to be a proxy for the spatial distribution of first-feeding sprat larvae. The vast majority of particles was released inside the $40 \mathrm{~m}$ isobath of the four major Baltic spawning grounds: Arkona Basin, Bornholm Basin, Gdansk Deep, and Gotland Basin (Fig. 1b). All drifters were seeded and forced to remain within the 5-10 m depth layer, because feeding sprat larvae predominantly occur in surface waters and appear not to exhibit clear vertical migration patterns (Voss et al. 2005). Each year, particle cohorts representing batches of first-feeding, passively drifting sprat larvae were released on 21 April (day 111) and then every 10 days until 10 July (day 191) to cover the entire average spawning season of Baltic Sea sprat (Köster and Möllmann 2000; Karasiova 2002). Each of these nine larval pulses per year consisted of 2671 particles that were seeded in regular spatial intervals of about $5 \mathrm{~km}$ (Fig. 1b). 
Fig. 1. Distributions of 2671 Lagrangian particles (black dots) released on 10 July (day 191) within areas of Baltic Sea sprat (Sprattus sprattus) spawning effort and tracked for 50 days in (a) 1997 and (b) 1998. The bathymetry of the study area is shown in panel $a$; the particle seeding pattern (grey dots) is depicted in panel $b$. Water abbreviations: AB, Arkona Basin; BB, Bornholm Basin; GB, Gotland Basin; GD, Gdansk Deep. Land abbreviations: DK, Denmark; Ger, Germany; Lat, Latvia; Li, Lithuania.

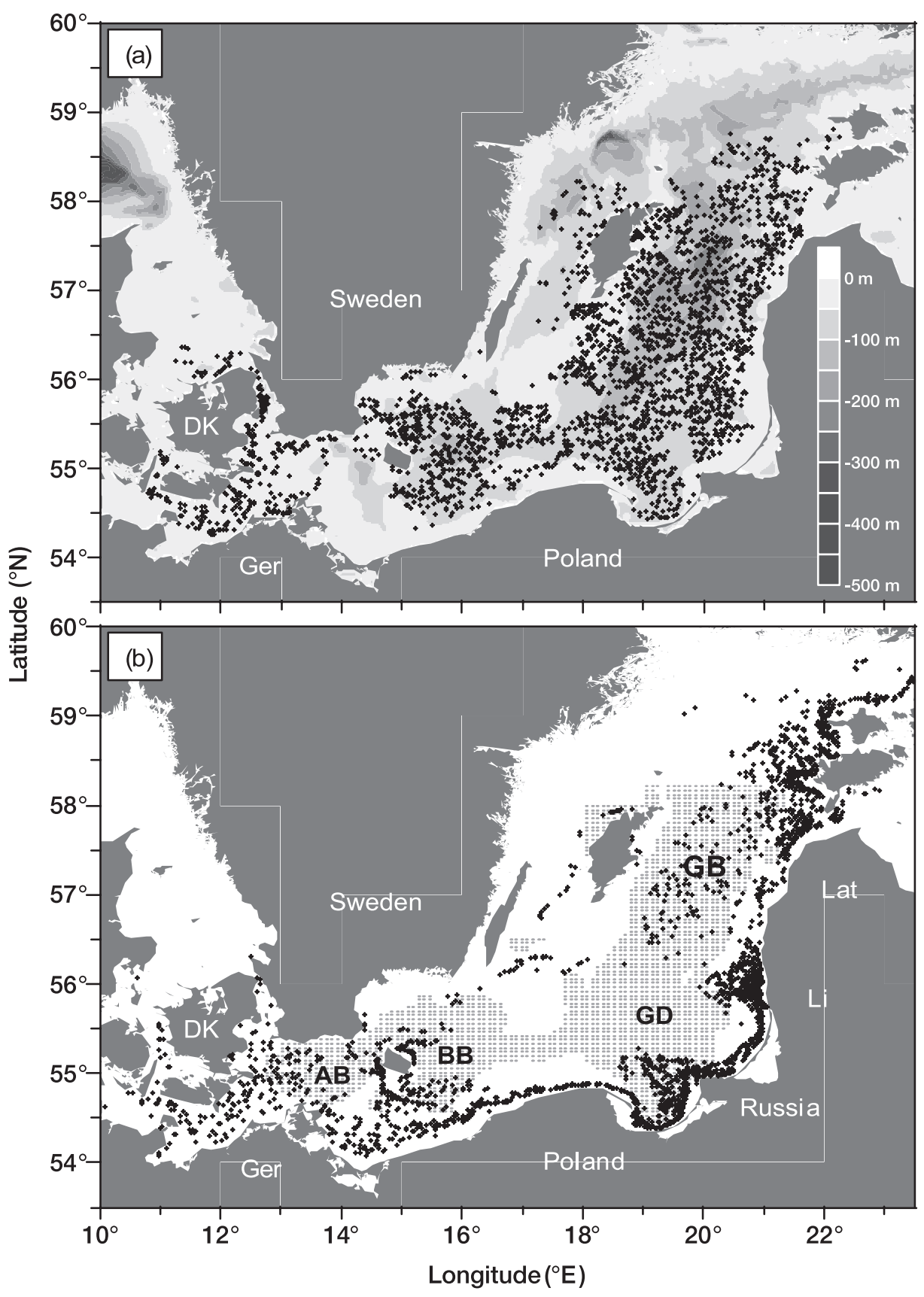

Two different approaches were tested regarding the end of the simulations. First, particles were tracked through the model domain for variable drift periods of 50-130 days, until a common collection date on 28 August (day 240). This arbitrary date was chosen to compromise sufficient drift times for late-released larval batches while avoiding too long drift periods for oldest larvae, because active swimming for the latter becomes likely. In a second approach, drifters were tracked for fixed periods of 50 days, entailing nine different collection dates (9 June to 28 August).

For an integrated view of annual drift patterns, daily bottom depths were averaged by year and release date across all
2671 particles, regardless of their individual positions in model domain. Then, because we were interested in anomalies rather than absolute values, average daily bottom depths $\left(D_{i k l}\right)$ were standardized to zero mean and unit deviation across all 25 years modelled (i.e., $S_{i k l}=\left(D_{i k l}-m_{k l}\right) \mathrm{SD}_{k l}^{-1}$, where $S_{i k l}$ is the standardized bottom depth of the $i$ th year, the $k$ th release, and the $l$ th day; and $m$ and SD are the dayand release-specific mean and standard deviation of bottom depth across all 25 years, respectively). Finally, daily standardized bottom depths were averaged over the considered simulation period (i.e., either over 50 days after release (fixed drift periods) or over release-specific variable drift 
periods (fixed collection date)). Annual, mean, standardized bottom depths are hereafter referred to as bottom depth anomalies (BDAs).

\section{Temperature, recruitment, and larval abundance}

Temperatures in the Baltic Sea were compiled from the International Council for the Exploration of the Sea (ICES) Oceanographic Database (http://www.ices.dk/ocean/), containing two main data sets of $(i)$ surface temperatures $(0-10 \mathrm{~m})$ and (ii) depth-specific CTD (conductivity-temperaturedepth) and bottle measurements. From the combined data, we selected all available temperatures between 1974 and 2003 within the area of the major Baltic Sea sprat stock abundance $\left(53^{\circ}-60^{\circ} \mathrm{N}, 13^{\circ}-23^{\circ} \mathrm{E}\right.$, ICES $\left.2005 b\right)$. Data were subsequently aggregated to obtain monthly means per year and $10 \mathrm{~m}$ depth stratum down to a water depth of $70 \mathrm{~m}$ (i.e., 0 to $<10,10$ to $<20, \ldots, 60$ to $<70 \mathrm{~m}$ ). Temperature means were derived from, on average, 223 observations available per month, depth stratum, and year.

Both temperature and BDA time series were correlated to the abundance of age- 0 sprat during the 3rd quarter of each year in the entire Baltic Sea (ICES subdivisions 22-32). The abundance estimates (1974-2003) were taken from the most recent area-aggregated, multispecies virtual population analysis (MSVPA; ICES 2005b), which also provided the updated time series of sprat SSB. Data on larval sprat abundance were available from various ichthyoplankton surveys in the Bornholm Basin, Gdansk Deep, and Gotland Basin between 1979 and 1999 (stations deeper than $60 \mathrm{~m}$ ), as described by Köster et al. (2003).

\section{Baltic Sea Index (BSI)}

To obtain a general impression of how atmospheric conditions over the Baltic Sea influence transport and temperature patterns, we applied the BSI (Lehmann et al. 2002), which is defined as the difference of normalized sea level pressure anomalies between Oslo (Norway) and Szczecin (Poland). Positive indices correspond to anomalous sea level pressures associated with westerly winds, whereas negative indices indicate predominantly easterly winds over the Baltic Sea. BSIs were recorded in $3 \mathrm{~h}$ intervals, but later averaged over the desired periods of larval drift simulations.

Correlations between time series of BDA, temperature, BSI, and sprat recruitment were studied using Pearson's bivariate, two-sided correlation coefficient (SPSS 13.0.1, SPSS Inc., Chicago, Illinois).

\section{Results}

\section{Transport (BDA) and recruitment}

For all nine drifter cohorts per year, final particle positions on day 240 (28 August) were indicative of considerable interannual differences in Baltic circulation patterns. Two main scenarios could be distinguished: (i) years of predominant particle retention within the central deep basins, likely induced by prevailing weak to variable easterly winds in summer (e.g., 1997; Fig. 1a), and (ii) years of large-scale particle displacement and dense accumulation along southern, southeastern, and eastern Baltic coastlines, probably as a consequence of prevailing strong to variable westerly winds in summer (e.g., 1998; Fig. 1b). Particle displacement
Fig. 2. Release-specific bottom depth anomalies (BDAs) derived from long-term Lagrangian particle simulations. Shaded lines correspond to BDAs derived from releases 1-8 (day 111 - day 181), while BDAs based on the last release 9 (day 191) is shown by the dash-dotted line. $\mathrm{BDA}_{9}$ was best correlated to Baltic Sea sprat (Sprattus sprattus) 0-group abundance (solid dark line), which was estimated by area-aggregated multispecies virtual population analysis (MSVPA).

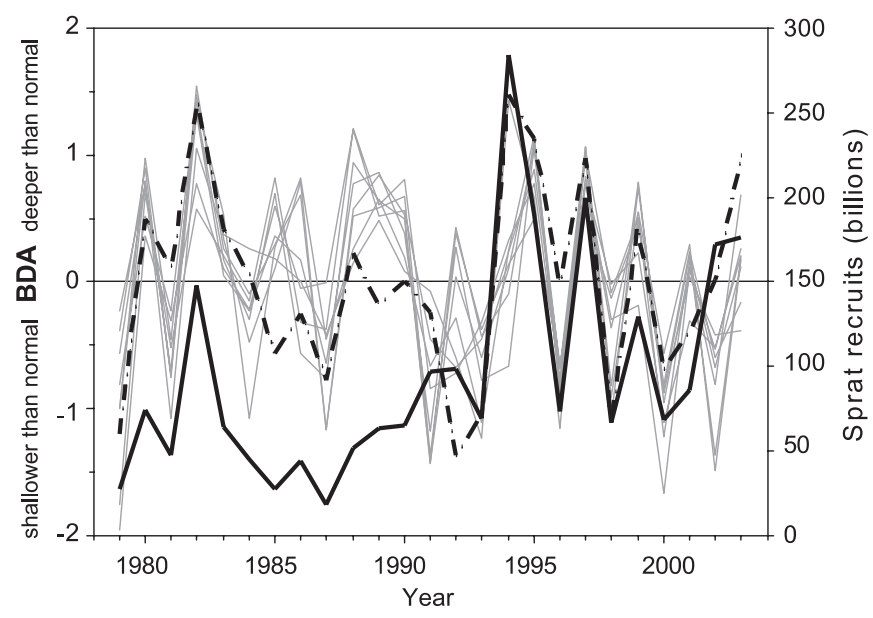

towards Swedish coastlines (westward drift) was generally negligible.

Release-specific BDAs $\left(\mathrm{BDA}_{1-9}\right)$ reflected these interannual differences well, with positive and negative BDAs indicating years when the majority of sprat larvae likely drifted over deeper-than-normal or shallower-than-normal waters, respectively, (Fig. 2). Indices derived from variable drift periods (fixed collection on 28 August) were all significantly cross-correlated $(P<0.05)$, in contrast with indices based on fixed 50-day drift periods, where significant crosscorrelations did not exceed two subsequent release dates (e.g., $\mathrm{BDA}_{3}$ was correlated to $\mathrm{BDA}_{2}$ and $\mathrm{BDA}_{4-5}$, but not to $\left.\mathrm{BDA}_{6-9}\right)$. Within a given drift period, the coefficient of variation (CV) of daily average bottom depths ranged between $4 \%$ and $32 \%$ (temporal transport variability).

Drift indices based on early release dates $1-7\left(\mathrm{BDA}_{1-7}\right)$ were not significantly correlated to sprat age- 0 abundance $(P>0.05)$, irrespective of fixed or variable simulation periods. In contrast, highly significant positive correlations occurred between sprat recruitment and $\mathrm{BDA}_{8}$ (release 30 June, $P=0.003, r^{2}=0.32$ ) and $\mathrm{BDA}_{9}$ (release 10 July, $P<0.001$, $r^{2}=0.50$ ). For the latter, an exponential function of the form $y=a b^{x}$ best fitted the data $\left(r^{2}=0.64\right)$. However, the residuals of the fitted $\mathrm{BDA}_{9}$-recruitment curve showed a clear decadal pattern; residuals between 1979 and 1990 were all negative, in contrast with all positive residuals between 1991 and 2003 (except 1996). If separate exponential curves were fitted to these two periods, $\mathrm{BDA}_{9}$ explained $92 \%$ of the variability between 1979 and 1990 and $84 \%$ between 1991 and 2003 (Fig. 3). The shift in the relationship between BDA, and recruitment coincided with the strong increase in Baltic Sea sprat SSB at the end of the 1980s (Fig. 4).

\section{Temperature and recruitment}

Out of 84 correlations (12 months $\times 7$ depth strata), temperature was significantly $(P<0.05)$ and positively corre- 
Fig. 3. Relationship between bottom depth anomaly $9\left(\mathrm{BDA}_{9}\right)$ and Baltic Sea age-0 sprat (Sprattus sprattus) recruitment $(R)$. Exponential curves $\left(R=a \cdot b^{\mathrm{BDA}_{9}}\right)$ best fitted the periods 1979 $1990\left(r^{2}=0.92\right.$, squares $)$ and 1991-2003 $\left(r^{2}=0.84\right.$, circles $)$.

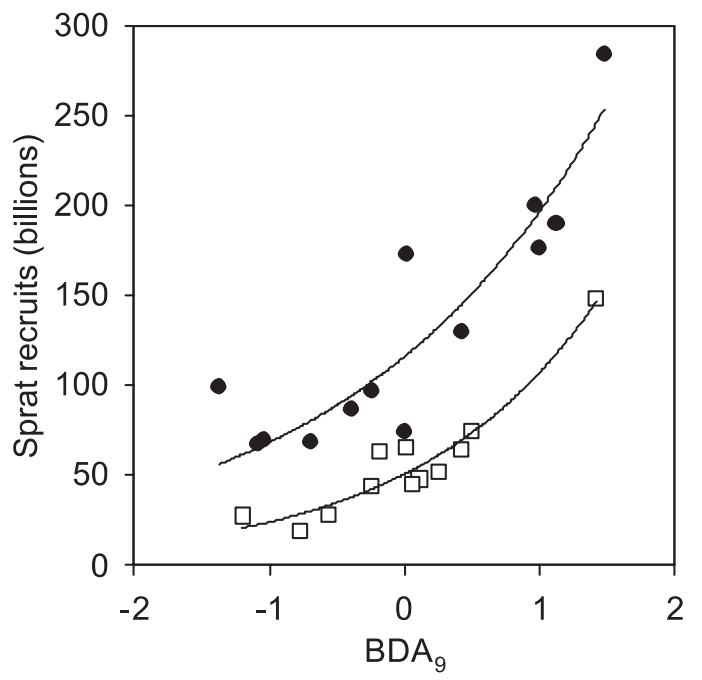

Fig. 4. Time series of Baltic Sea sprat (Sprattus sprattus) spawning stock biomass (SSB, solid line) and mean larval abundance (shaded line) in the main Baltic spawning grounds Bornholm Basin, Gdansk Deep, and Gotland Basin between May and July.

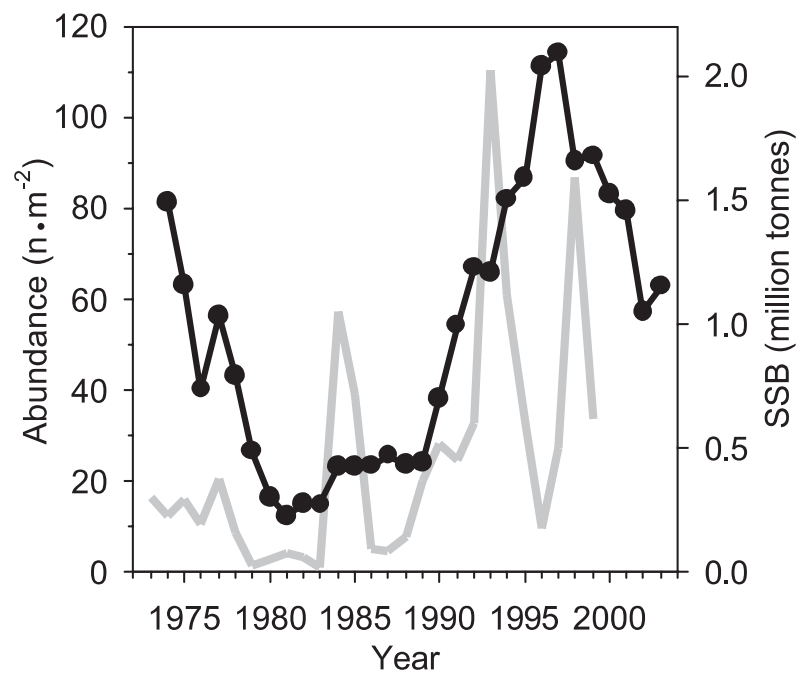

lated to Baltic Sea sprat recruitment success in 31 cases, thereby showing a characteristic month- and depth-specific pattern (Fig. 5). Significant temperature-recruitment correlations were already observed in January and in depths between 40 and $70 \mathrm{~m}\left(r_{\max }^{2}=0.34\right)$. February temperatures were uncorrelated to recruitment. Between March and July, significant but weak correlations to recruitment developed mostly in midwater depths $\left(20-60 \mathrm{~m}, r_{\max }^{2}=0.21\right)$, with April correlations having the broadest depth range. From July to August, correlations shifted notably to surface waters, with August temperatures in 0-10 m explaining 66\% of sprat recruitment variability between 1974 and 2003 (Fig. 5). A quadratic fit to the data, however, explained $73 \%$ of the overall recruitment variability. A shift in the relation-
Fig. 5. Summarizing the month- and depth-specific temperaturerecruitment correlations of Baltic Sea sprat (Sprattus sprattus) based on 30 years of observations (1974-2003). Shading and isolines correspond to $r^{2}$ and $P$ values, respectively, while crosses refer to the data grid points used to create the contour plot (i.e., Kriging).

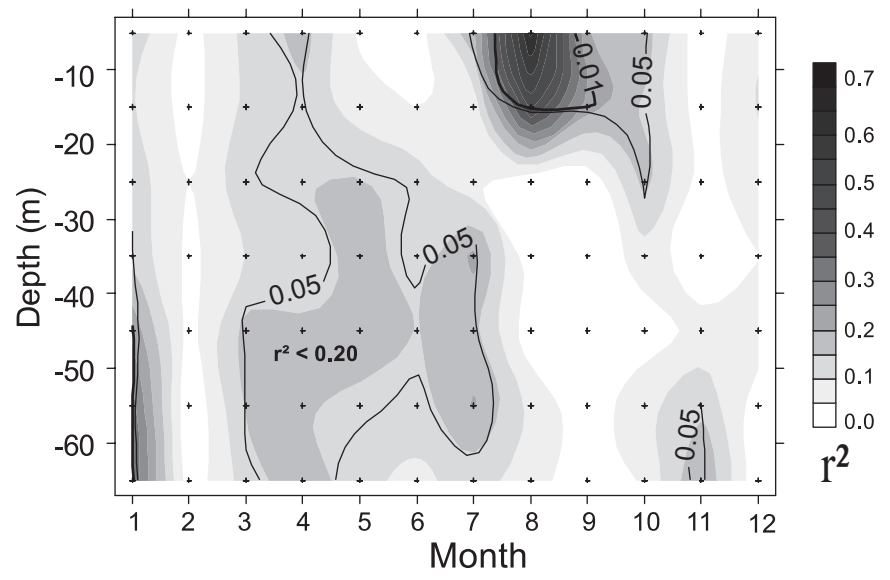

ship between decades, as observed for $\mathrm{BDA}_{9}$, was not apparent for temperature. Surface temperatures were still significantly correlated to recruitment strength in September and October $\left(r_{\max }^{2}=0.22\right)$, whereas in November, a weak but significant correlation reappeared in deeper water layers $(50$ $70 \mathrm{~m}, r_{\max }^{2}=0.20$; Fig. 5).

The BSI averaged between 10 July and 28 August (days 191-240) was found to be significantly and negatively correlated to the corresponding drift index $\left(\mathrm{BDA}_{9}, P=0.001, r^{2}=\right.$ $0.38)$ and surface temperature in August $\left(P=0.003, r^{2}=\right.$ 0.35 ; Fig. 6). The relationships indicated that differences in sea level pressure associated with westerly winds (positive BSIs) induced both coastal particle transport and relatively cold surface temperatures, while negative BSIs and easterly winds were conducive to warm years and particle retention.

\section{Recruitment models}

The strong cross-correlation between surface temperature in August and $\mathrm{BDA}_{9}\left(P<0.001, r^{2}=0.46\right)$ precluded the inclusion of both variables in a common recruitment model. SSB alone explained $28 \%$ of the recruitment variability $(P=$ $0.007)$ and was significantly cross-correlated to August temperature $(P=0.023)$ but not to $\mathrm{BDA}_{9}(P=0.75)$. We therefore constructed two different models, the first using $\mathrm{BDA}_{9}$ and SSB and the second using only August surface temperature $(T)$ as independent variables to predict the MSVPA estimates of sprat age- 0 abundance (Table 1 ). The used model functions were

$$
\begin{aligned}
& \text { age } 0 \text { sprat }=a^{\mathrm{BDA}_{9}}+b \cdot \mathrm{SSB} \\
& \text { age } 0 \text { sprat }=a \cdot T^{2}+b \cdot T
\end{aligned}
$$

The explained variability in the $\mathrm{BDA}_{9}+\mathrm{SSB}$ model was 82\% (1979-2003; Fig. 7a) and therefore slightly better than the recruitment prediction using August temperature only (1974-2003, $r^{2}=0.73$; Fig. 7b). However, both models predicted different years of sprat recruitment success differently and with a differing quality of prediction. While sprat recruitment was considerably underestimated by the 
Table 1. Parameter estimates and their 95\% confidence limits, significance levels, and $r^{2}$ values for the two recruitment models using

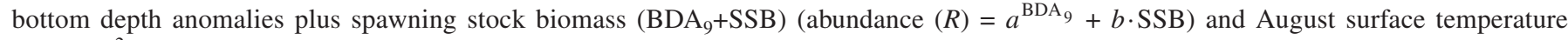
$\left(R=a \cdot T^{2}+b \cdot T+\right.$ constant $)$ to predict the multispecies virtual population analysis (MSVPA) estimates of age-0 sprat, Sprattus sprattus, in the entire Baltic Sea.

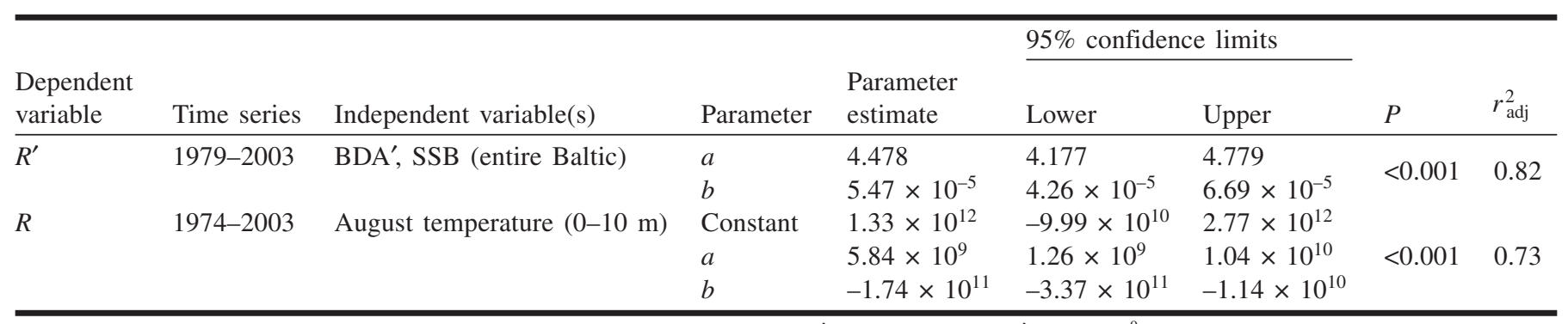

Note: Transformed variables were used to fit the $\mathrm{BDA}+\mathrm{SSB}$ model (i.e., $\mathrm{BDA}^{\prime}=\mathrm{BDA}_{9}+2$ and $R^{\prime}=R \times 10^{-9}$ ).

Fig. 6. Relationship between the Baltic Sea Index (BSI) and (a) bottom depth anomaly (BDA, 1979-2003, $r^{2}=0.38$ ) and (b) surface temperature in August (1974-2003, $\left.r^{2}=0.35\right)$. Data indicated with parentheses were years that were not included in the regression.
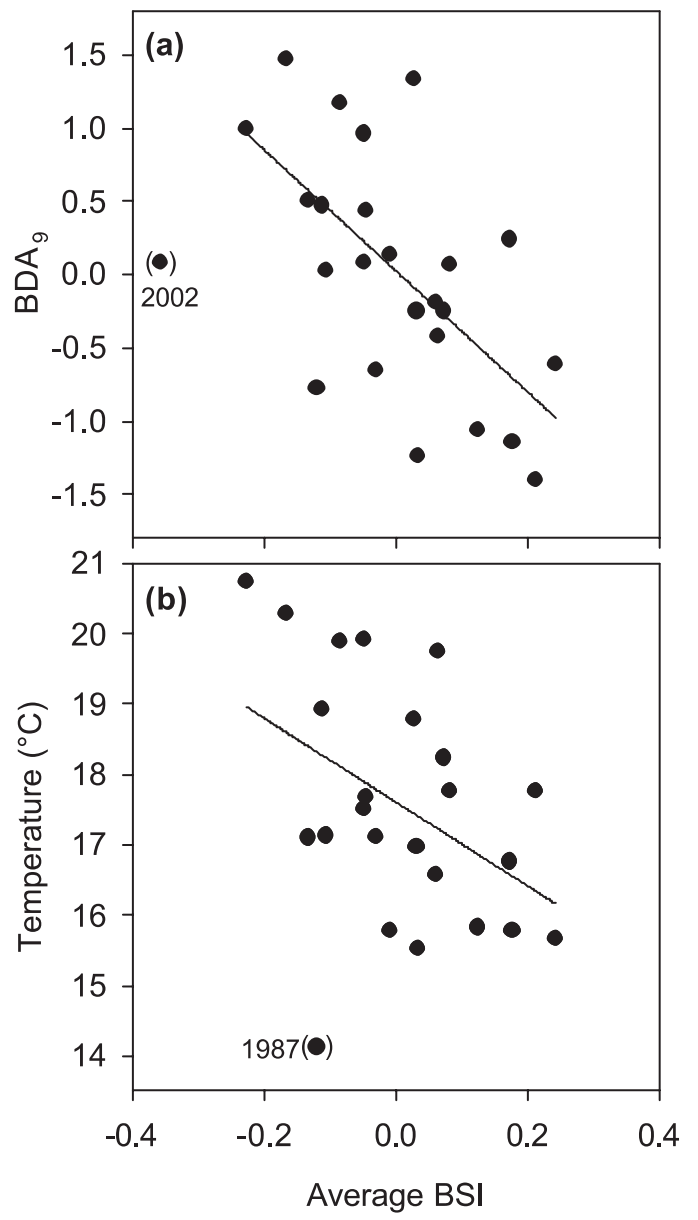

$\mathrm{BDA}_{9}+\mathrm{SSB}$ model in 1996 and 2002, the quadratic temperature model yielded much closer estimates. Conversely, temperature-based predictions were considerably poorer than the $\mathrm{BDA}_{9}+\mathrm{SSB}$ model in 1994 and particularly in 2001 (Fig. 7).

Interestingly, residuals scaled by observed recruitment numbers were significantly and negatively correlated to the
Fig. 7. Time series of observed (triangles, shaded line) and predicted (circles, solid line) Baltic Sea sprat (Sprattus sprattus) recruitment. (a) BDA+SSB (bottom depth anomaly plus spawning stock biomass) model explaining $82 \%$ of the recruitment variability between 1979 and 2003. (b) Temperature model (August, $0-10 \mathrm{~m}$ ) explaining $73 \%$ of recruitment variability between 1974 and 2003.

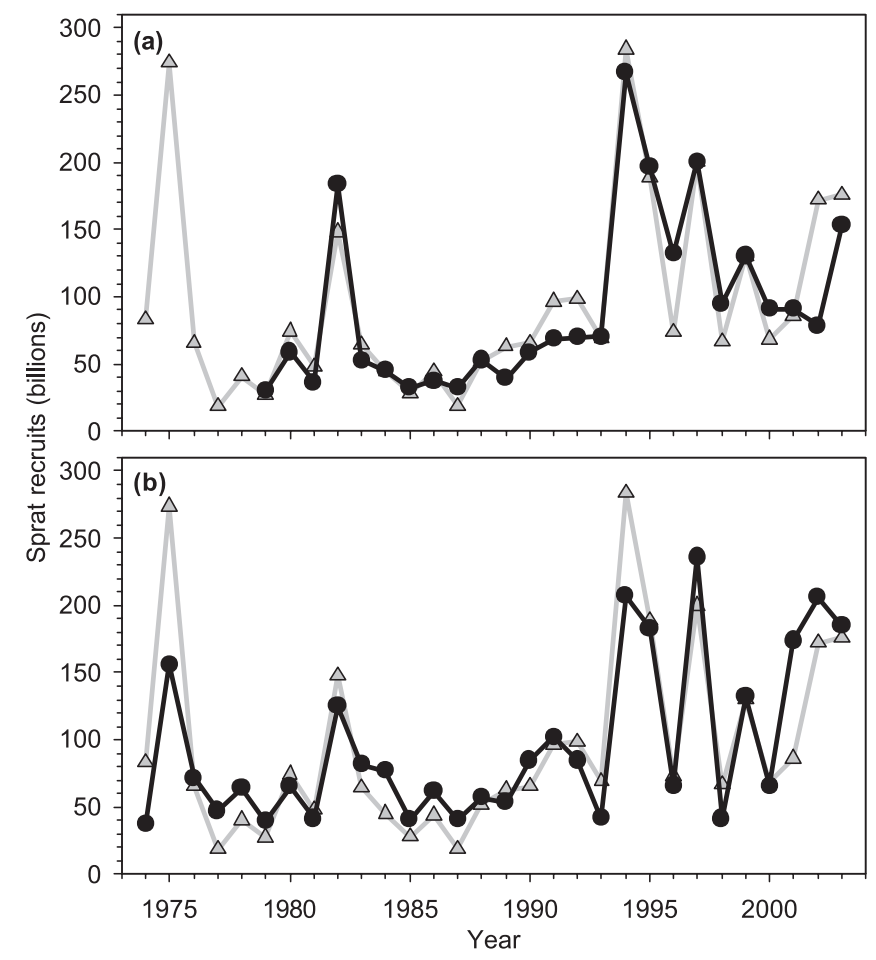

variability around $\mathrm{BDA}_{9}\left(P=0.02, r^{2}=0.36\right)$, indicating that years of highly variable transport patterns increasingly led to recruitment overestimation (Fig. 8).

\section{Discussion}

BDA as a drift proxy

We found BDAs a meaningful way to condense and quantify the large amounts of information produced by long-term Lagrangian simulations. BDAs reflected well the variable degree of annual particle transport from the central deep 
Fig. 8. Relative deviations of recruitment predictions made by the BDA+SSB (bottom depth anomaly plus spawning stock biomass) model as a function of $\mathrm{BDA}_{9}$ variability ( $\mathrm{SD} \mathrm{BDA}_{9}$; i.e., standard deviation of standardized bottom depths between days 191 and 240), showing increased recruitment overestimation for years of high drift variability $\left(P=0.02, r^{2}=0.36\right)$.

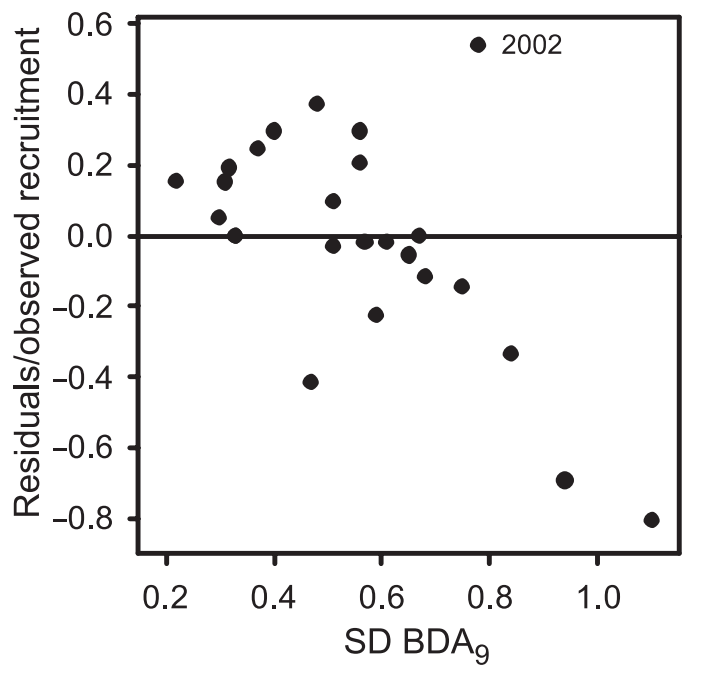

spawning basins of the Baltic Sea to shallower coastal waters. In addition, averaging daily standardized bottom depths along particle trajectories effectively integrated the drift information over the entire simulation period, which was advantageous over our previous approach using only the final horizontal particle positions (Baumann et al. 2004). This did not affect the key results, though, which were similar for both studies and indicated that years of relative particle retention or coastal displacement corresponded to relative sprat recruitment success or failure, respectively. Both studies were also consistent in finding the strongest correlations to recruitment for particles released late in the season.

However, when moving from particles to living organisms, inferences drawn from Lagrangian simulations rely on the assumption that passive drifter trajectories reflect the average transport patterns of the planktonic species or life stage studied. In demersal fish like cod or flatfish, juvenile settlement concludes the susceptibility to ocean circulation and thus sets a natural limit to drift studies (e.g., 65 days; Hinrichsen et al. 2003). Such a limit is not as readily defined in pelagic species like sprat. The onset of active swimming behaviour or schooling may not necessarily preclude Lagrangian drift simulations if late larvae or early juveniles keep moving randomly within a water body that is subject to predictable physical forcing. For example, Allain et al. (2003) successfully used a hydrodynamic model to infer likely origins of approximately 100-day-old and $80 \mathrm{~mm}$ long (Cermeno et al. 2003) juvenile European anchovy, Engraulis encrasicolus, in the Bay of Biscay. For the Baltic Sea, Hinrichsen et al. (2005) compared average Lagrangian drifter distributions with field data on 0-group sprat abundance, as determined by annual hydroacoustic surveys. They found model and field distributions in generally good accordance, with the highest mean October abundance of sprat juveniles along the southern and eastern Baltic coasts. The authors also reported that the inclusion of simulated larval vertical migration did not produce contradictory results. It may, therefore, be justified to assume that average transport patterns of sprat larvae and early juveniles were generally reflected by the present drift model.

Still, longer simulation periods increase uncertainty, which could have been a contributory but not the only reason for the lack of correlation between early released particles and recruitment strength, because fixed and variable drift periods produced similar results. Furthermore, both approaches did not show a gradual but a very sudden shift from nonsignificant to highly significant BDA-recruitment correlations from early- (April-June) to late-released particles (July), possibly reflecting the seasonally different contribution of larval production to recruitment. In other words, sprat larvae born early in the season may play a negligible role in the recruitment process, while new sprat year classes appear to consist predominantly of individuals born relatively late in the season. The hypothesis is supported by recent findings of Voss et al. (2005), who studied larval sprat survival and condition in relation to food availability in the central Baltic Sea during 2002. The authors presented evidence that the late larval stages critically relied on the abundance of larger copepodites and adult copepods, which were scarce in April-May but significantly more abundant in June-July 2002. In addition, Baumann et al. (2006a) inferred distributions of days-of-first-feeding (DFF, a proxy for hatch date) from otolith microstructure analyses in newly recruited 0-group sprat caught in October 2002 in the Baltic Sea. Depending on the Baltic region, DFF distributions of sprat survivors peaked between the end of June and mid-July 2002, which is consistent with the present conclusion.

If recruitment levels are mainly determined by variable survival patterns of individuals born late in the season, what potential mechanisms could cause the observed dependence on circulation variability? Previous studies on other species and different marine systems (reviewed by Sissenwine 1984; Leggett and Deblois 1994) have mostly attributed the coupling between recruitment success and advective processes to food availability (e.g., Borja et al. 1998; Skogen 2005; Zeldis et al. 2005) or feeding success (Crecco and Savoy 1987). For Baltic Sea cod (Gadus morhua) larvae, Hinrichsen et al. (2003) showed that retention to but also advection out of the central Bornholm Basin could have beneficial effects to survival, depending on the season and the abundance of the calanoid copepod Pseudocalanus acuspes. For Baltic Sea sprat, stock size and 0-group numbers (Kornilovs. et al. 2001; Alheit et al. 2005) appear to be correlated to long-term trends in abundance of the two most important prey species, Acartia spp. and Temora longicornis, which showed significant, temperature-related increases during the 1990s (Möllmann et al. 2000). However, these observations did not resolve potential differences between Baltic basins and coastal areas. The latter normally support a higher primary and secondary production, which appears contradictory to our findings of poor recruitment levels associated to years of high larval onshore transport.

Apart from influencing transport, variable forcing conditions also affect turbulence, which is potentially important for larval feeding success (MacKenzie et al. 1994). On the population level, however, this mechanism is not unequivocally supported by field studies and appears to be of less im- 
Fig. 9. Relationship between sprat (Sprattus sprattus) recruitment success and the number of Lagrangian drifters (out of 2671) that had at least one next neighbour within a $0.5 \mathrm{~km}$ radius of their final position. A significant $\left(r^{2}=0.62, P=0.001\right)$ logarithmic relationship was found only for the period 1991-2003 (solid circles, solid line). The nonsignificant relationship between 1979 and 1990 (open circles) is shown by a broken line. Particles were released on 10 July (release 9) and tracked for 50 days.

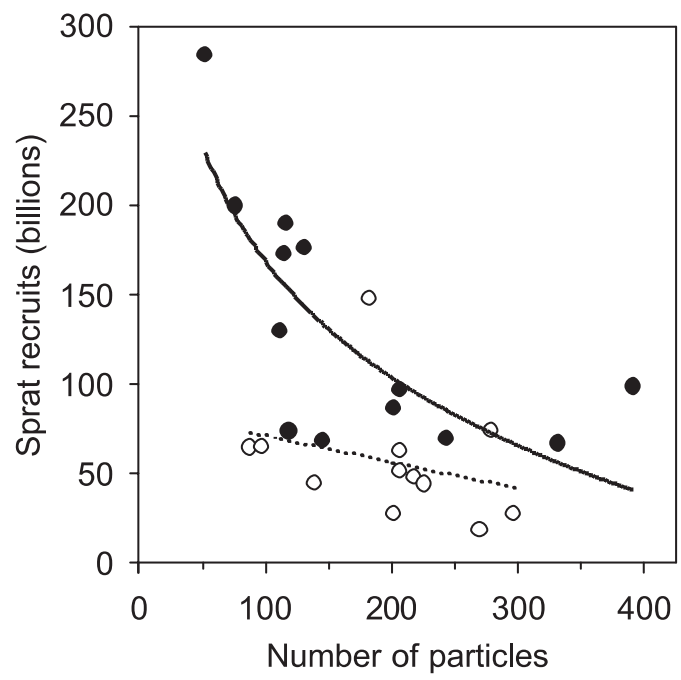

portance for older larvae and early juveniles, where turbulence levels probably need to be unnaturally high to hamper feeding success (MacKenzie 2000).

It has also been suggested that density-dependent processes operating during the late larval - early juvenile stages may substantially modify recruitment levels (Cushing 1974; Leggett and Deblois 1994). To test this hypothesis with our drift model, we calculated the distance between each particle and its next neighbour on 28 August (end of simulation). During years of large-scale coastal transport (e.g., 1998), particles were found in much denser aggregations than during retention years (e.g., 1997), with particle density being significantly $(P<0.05)$ and inversely related to recruitment strength (Fig. 9). The fact that such a relationship was only apparent throughout the last decade may be explained by the, on average, higher larval abundance during the 1990s. In addition, Baumann et al. (2006b) compared otolith-based growth rates of sprat recruits caught in October 2003 in the western Baltic Sea with those of pre-recruits caught at the end of August in very shallow coastal waters. The authors presented evidence that a sudden growth decline observed exclusively in pre-recruit otoliths likely resulted from severely depleted food resources. It could thus be argued that coastal areas may not always comprise the most suitable nursery grounds for Baltic Sea sprat, particularly if high summer temperatures in shallow waters lead to increased energetic demands and thus food requirements (Houde 1989) of post-larvae and early juveniles.

The strong increase of the sprat spawning stock at the end of the 1980 s may have increased the potential impact of transport-related, density-dependent processes. This is supported by the fact that over a similar range of BDA values, the magnitude of recruitment fluctuations almost doubled from the 1980 s to the 1990 s. It does not imply a greater sen- sitivity of recruitment to transport, since BDAs during the 1980 s were more closely related to recruitment variability than during the 1990s. However, although SSB may have been the most important factor responsible for the shift in the drift-recruitment relationship, it co-occurred with a whole suite of changes in the Baltic ecosystem that affected all trophic levels (Alheit et al. 2005). Particularly, the unknown effects of pronounced shifts in Baltic zooplankton composition and dynamics (Möllmann et al. 2000) could have increased unexplained variability around the driftrecruitment relationship.

\section{Temperature and recruitment}

As with transport, studies that show significant temperature-recruitment correlations are numerous across species and marine systems (e.g., Campana 1996; Fowler and Jennings 2003; Zeldis et al. 2005), but often a multitude of interrelated mechanisms, acting on different life stages, are proposed to have caused these relationships. Temperature-enhanced growth rates certainly appear to reduce cumulative predatory losses in early larval populations (Pepin 1991; Heath 1992), as formulated by the "bigger-isbetter", the "stage-duration", or "growth-selective predation" hypotheses (Takasuka et al. 2004). In many cases, the temperature effect of enhanced survival through higher growth rates is probably augmented by temperature-dependent zooplankton dynamics (Limburg 1996). For Baltic Sea sprat, significant temperature effects on recruitment strength have so far been attributed to the limited tolerance of sprat eggs and early larvae to low midwater temperatures after severe winters (Nissling 2004).

The present analysis of month- and depth-specific temperature-recruitment relationships has broadened our perception of when and where ambient temperature conditions interact with recruitment variability. Three main cores of such temperature-recruitment relationships were found: the first is in January and at depths below $40 \mathrm{~m}$, which may reflect positive effects on the gonad development of prespawning adults, which are known to overwinter in the deep Baltic basins (Stepputtis et al. 2003). The second core encompassed correlations in midwater depths between March and July and is consistent with the body of published work on temperature-dependent sprat egg and early larval survival (Karasiova and Zezera 2000; Köster et al. 2003). However, the third core has not previously been reported and occurred between July and October in Baltic surface waters, with August relationships having a much higher explanatory power than all temperature correlations earlier in the year. This indicates that temperature-related survival processes during the late summer months, and therefore throughout or after metamorphosis (Baumann et al. 2005, 2006a), explain most of the recruitment variability in Baltic Sea sprat. Furthermore, the fact that August and September correlations occurred only in surface waters may reflect the predominant vertical distribution of pre-recruit sprat late in summer.

Although Houde (1992) found survival until metamorphosis to be 45 times lower in marine than in freshwater fish, and consequently suggested that "in marine species larval stage dynamics will have a greater influence on recruitment success", studies concluding just the opposite have become numerous. Bradford (1992) analysed abundance data of fish 
eggs and larvae compiled from the literature and suggested that "recruitment levels are fixed after the early-larval period", while Leggett and Deblois (1994) more explicitly proposed that "interannual variability in survival during the juvenile life stage is the most important contributor to recruitment variability". Small pelagic clupeoids appear to fit into this concept, as indicated by the present and other recent studies (e.g., by Wilhelm et al. 2005 on Cape anchovy, E. encrasicolus, and Takahashi and Watanabe 2005 on Japanese anchovy, Engraulis japonicus).

In the case of post-larval Baltic Sea sprat, we need to reconsider the mechanisms responsible for the apparently strong temperature-recruitment relationship. It is noteworthy that all of the established temperature-growth-survival hypotheses for fish larvae imply size- or growth-rate-selective predation to act as the ultimate mortality agent. Following this rationale, years of high surface temperatures in August would increase population growth and thus body size at the end of summer, which then somehow confers a survival advantage with respect to predation. However, the only major predator of Baltic sprat was assumed to be Baltic cod (Köster et al. 2003), before stocks dramatically declined because of a combination of climate-induced recruitment failures and overfishing (Bagge and Thurow 1993). This has caused an estimated fivefold decrease in predation mortalities of 0-group sprat from the mid 1970s to the early 1990s and thereafter (ICES 2005b), which did not affect the persistently strong temperature-recruitment relationship. Recent studies on Atlantic cod in the North Sea also suggested that relatively small prey size differences (e.g., due to temperature) have very limited consequences for the total predation mortality (Floeter and Temming 2003). Whether other Baltic piscivores, particularly in shallow coastal areas, can significantly prey on 0-group sprat remains to be demonstrated (e.g., Patokina and Feldman 1998). We argue that the predation by Atlantic cod on post-larval and juvenile sprat cannot be regarded as the major mechanism underlying the observed strong coupling between recruitment and late summer surface temperature.

However, bigger sizes due to accelerated growth in summer may not necessarily grant immediate survival benefits but could also lead to lower mortality throughout the subsequent first winter (e.g., Henderson et al. 1988). Smaller fish have lower energy reserves than bigger conspecifics and could therefore be physiologically less tolerant against low temperatures during overwintering (Sogard 1997). This may be particularly important in a species like sprat, for which the Baltic Sea comprises the northern extreme of its geographical distribution (MacKenzie and Köster 2004). We note that our approach of considering sprat age-0 estimates does not rule out this possibility, because MSVPAs are predominantly driven by catch-at-age data starting at age 1 and are therefore insensitive to potential interannual variations in age- 0 overwinter mortality. To assess the magnitude of this potential mechanism, future studies should compare independent abundance time series of sprat recruits prior to and after their first winter.

The strong correlations among long-term data of surface temperature, modelled transport patterns, and sprat recruitment variability advocate that new year classes of Baltic Sea sprat are (i) mainly composed of individuals born late in the season and (ii) determined in strength by processes acting during the late larval and early juvenile stages. Furthermore, recruitment and atmospheric processes appear to be tightly coupled in the Baltic Sea. The significant relationships between both recruitment proxies and the BSI suggested that temperature and transport have a combined and coherent influence on sprat recruitment. Positive BSIs are characteristic for prevailing westerly winds (Lehmann et al. 2002), which cause eastward and southeastward larval transport and result in lower summer surface temperatures because of increased cloud cover and precipitation (i.e., maritime weather). Conversely, larval retention and high summer surface temperatures appear to be linked through prevailing weak easterly winds (negative BSIs; i.e., continental weather). For these two scenarios, the temperature and the drift model were reliably consistent, suggesting that recruitment levels can be predicted with relatively high confidence. However, a potential decoupling of temperature and transport may happen and will result in inconsistent and therefore less confident predictions (e.g., 2001 and 2002). The drift model may presently be advantageous to the temperature model, given (i) that it explicitly includes SSB as a biologically sensible variable, (ii) that it is based on a reasonable and testable mechanism (i.e., density-dependent processes in coastal areas), and (iii) because of its higher explanatory power.

Correlational studies are useful means to detect long-term trends and general relationships between environmental variables and fish recruitment, which are instrumental for hypothesis generation (e.g., MacKenzie and Köster 2004; Ottersen et al. 2006). Process-oriented field and laboratory studies including all pre-recruit life stages are inevitable for hypothesis testing and exploration of the mechanisms driving such environment-recruitment correlations, which will contribute to improved recruitment models less prone to postpublication failure. The intended revenue of such efforts may be an increased readiness of fisheries managers to include environmentally based projections into regular assessment procedures.

\section{Acknowledgements}

Owing to the constructive criticism of the two anonymous reviewers, revising an earlier version of this paper became an enjoyable and creative process. The study was funded by the German Global Ocean Ecosystem Dyanmics (GLOBEC) program (FKZ 03F0320E).

\section{References}

Alheit, J., Möllmann, C., Dutz, J., Kornilovs, G., Loewe, P., Mohrholz, V., and Wasmund, N. 2005. Synchronous regime shifts in the Central Baltic and the North Sea in the late 1980s. ICES J. Mar. Sci. 62: 1205-1215.

Allain, G., Petitgas, P., Grellier, P., and Lazure, P. 2003. The selection process from larval to juvenile stages of anchovy (Engraulis encrasicolus) in the Bay of Biscay investigated by Lagrangian simulations and comparative otolith growth. Fish. Oceanogr. 12: 407-418.

Bagge, O., and Thurow, F. 1993. The Baltic cod stock: fluctuations and possible causes. ICES Mar. Sci. Symp. 198: 254-268.

Baumann, H., Hinrichsen, H.-H., Köster, F.W., and Temming, A. 2004. A new retention index for the central Baltic Sea: long- 
term hydrodynamic modelling used to study recruitment variability in central Baltic sprat, Sprattus sprattus. ICES CM 2004/L:02.

Baumann, H., Peck, M.A., and Herrmann, J.-P. 2005. Short-term decoupling of otolith and somatic growth induced by food level changes in post-larval Baltic sprat, Sprattus sprattus. J. Mar. Freshw. Res. 56: 539-547.

Baumann, H., Gröhsler, T., Kornilovs, G., Makarchouk, A., Feldman, V., and Temming, A. 2006a. Temperature-induced regional and temporal growth differences in Baltic young-of-theyear sprat, Sprattus sprattus. Mar. Ecol. Prog. Ser. 317: 225-236.

Baumann, H., Peck, M.A., Götze, E., and Temming, A. 2006 b. Starving early juvenile sprat, Sprattus sprattus L., in Western Baltic coastal waters: evidence from combined field and laboratory observations in August/September 2003. J. Fish Biol. (In press).

Bergstrøm, S., and Carlsson, B. 1994. River runoff to the Baltic Sea: 1950-1990. Ambio, 23: 280-287.

Borja, A., Uriarte, A., Egaña, J., Motos, L., and Valencia, V. 1998. Relationships between anchovy (Engraulis encrasicolus) recruitment and environment in the Bay of Biscay (1967-1996). Fish. Oceanogr. 7: 375-380.

Bradford, M.J. 1992. Precision of recruitment predictions from early life stages of marine fishes. Fish. Bull. 90: 439-453.

Campana, S.E. 1996. Year-class strength and growth rate in young Atlantic cod Gadus morhua. Mar. Ecol. Prog. Ser. 135: 21-26.

Cermeno, P., Uriarte, A., de Murguia, A.M., and Morales-Nin, B. 2003. Validation of daily increment formation in otoliths of juvenile and adult European anchovy. J. Fish. Biol. 62: 679-691.

Crecco, V.A., and Savoy, T.A. 1987. Effects of climatic and density-dependent factors on intra-annual mortality of larval American shad. Am. Fish. Soc. Symp. 2: 69-81.

Cushing, D.H. 1974. The possible density-dependence of larval mortality and adult mortality in fishes. In The Early Life History of Fish. Proceedings of an International Symposium held at the Dunstaffnage Marine Research Laboratory of the Scottish Marine Biological Association at Oban, Scotland. pp. 103-111.

Floeter, J., and Temming, A. 2003. Explaining diet composition of North Sea cod (Gadus morhua L.): prey size preference vs. prey availability. Can J. Fish. Aquat. Sci. 60: 140-150.

Fowler, A.J., and Jennings, P.R. 2003. Dynamics in 0+ recruitment and early life history for snapper (Pagrus auratus, Sparidae) in South Australia. Mar. Freshw. Res. 54: 941-956.

Heath, M.R. 1992. Field investigations of the early life stages of marine fish. Adv. Mar. Biol. 28: 1-174.

Henderson, P.A., Holmes, R.H.A., and Bamber, R.N. 1988. Sizeselective overwintering mortality in the sand smelt, Atherina boyeri Risso, and its role in population dynamics. J. Fish. Biol. 33: 221-233.

Hinrichsen, H.-H., Lehmann, A., St. John, M.A., and Brügge, B. 1997. Modelling the cod larvae drift in the Bornholm Basin in summer 1994. Cont. Shelf Res. 17: 1765-1784.

Hinrichsen, H.-H., Lehmann, A., Möllmann, C., and Schmidt, J.O. 2003. Dependency of larval fish survival on retention/dispersion in food limited environments: the Baltic Sea as a case study. Fish. Oceanogr. 12: 425-433.

Hinrichsen, H.-H., Kraus, G., Voss, R., Stepputtis, D., and Baumann, H. 2005. The general distribution pattern and mixing probability of Baltic sprat juvenile populations. J. Mar. Sys. 58: 52-66.

Houde, E.D. 1989. Comparative growth, mortality, and energetics of marine fish larvae: temperature and implied latitudinal effects. Fish. Bull. 87: 471-495.

Houde, E.D. 1992. Are marine and freshwater fish larvae different? ICES CM 1992/L:26.
ICES. 2005a. Report of the Baltic Fisheries Assessment Working Group. ICES CM 2005/ACFM:19.

ICES. 2005b. Report of the Study Group on Multispecies Assessment in the Baltic (SGMAB). ICES CM 2005/H:06.

Karasiova, E.M. 2002. Variability of sprat peak spawning and larvae appearance timing in the southeastern Baltic Sea during the past six decades. Bull. Sea Fish. Inst. Gdynia, 156: 57-67.

Karasiova, E.M., and Zezera, A.S. 2000. On influence of long-term variability of temperature regime in the Gdansk Deep of the Baltic Sea on the sprat reproduction and the offspring survival. ICES CM 2000/L:06.

Killworth, P.D., Stainforth, D., Webbs, D.J., and Paterson, S.M. 1991. The development of a free-surface Bryan-Cox-Semtner ocean model. J. Phys. Oceanogr. 21: 1333-1348.

Kornilovs, G., Sidrevics, L., and Dippner, J.W. 2001. Fish and zooplankton interaction in the Central Baltic Sea. ICES J. Mar. Sci. 58: 579-588.

Köster, F.W. 1994. Der Einfluß von Bruträubern auf die Sterblichkeit früher Jugendstadien des Dorsches (Gadus morhua) und der Sprotte (Sprattus sprattus) in der zentralen Ostsee. Ber. Inst. Meereskunde Kiel, 261.

Köster, F.W., and Möllmann, C. 2000. Egg cannibalism in Baltic sprat Sprattus sprattus. Mar. Ecol. Prog. Ser. 196: 269-277.

Köster, F.W., Möllmann, C., Neuenfeldt, S., St. John, M.A., Plikshs, M., and Voss, R. 2001. Developing Baltic cod recruitment models. I. Resolving spatial and temporal dynamics of spawning stock and recruitment for cod, herring, and sprat. Can. J. Fish. Aquat. Sci. 58: 1516-1533.

Köster, F.K., Hinrichsen, H.-H., Schnack, D., St. John, M.A., MacKenzie, B.R., Tomkiewicz, J., Möllmann, C., Kraus, G., Plikshs, M., Makarchouk, A., and Aro, E. 2003. Recruitment of Baltic cod and sprat stocks: identification of critical life stages and incorporation of environmental variability into stock-recruitment relationships. Sci. Mar. 67(Suppl.1): 129-154.

Leggett, W.C., and Deblois, E. 1994. Recruitment in marine fishes: is it regulated by starvation and predation in the egg and larval stages? Neth. J. Sea Res. 32: 119-134

Lehmann, A. 1995. A three-dimensional baroclinic eddy-resolving model of the Baltic Sea. Tellus, 47A: 1013-1031.

Lehmann, A., and Hinrichsen, H.-H. 2000. On the thermohaline variability of the Baltic Sea. J. Mar. Sys. 25: 333-357.

Lehmann, A., Krauss, W., and Hinrichsen, H.-H. 2002. Effects of remote and local atmospheric forcing on circulation and upwelling in the Baltic Sea. Tellus, 54A: 299-316.

Limburg, K.E. 1996. Growth and migration of 0-year American shad (Alosa sapidissima) in the Hudson River estuary: otolith microstructural analysis. Can. J. Fish. Aquat. Sci. 53: 220-238.

MacKenzie, B.R. 2000. Turbulence, larval fish ecology and fisheries recruitment: a review of field studies. Oceanol. Acta, 23: 357-375.

MacKenzie, B.R., and Köster, F.W. 2004. Fish production and climate: sprat in the Baltic Sea. Ecology, 85: 784-794.

MacKenzie, B.R., Miller, T.J., Cyr, S., and Leggett, W.C. 1994. Evidence for a dome-shaped relationship between turbulence and larval fish ingestion rates. Limnol. Oceanogr. 79: 1-16.

Möllmann, C., Kornilovs, G., and Sidrevics, L. 2000. Long-term dynamics of main mesozooplankton species in the central Baltic Sea. J. Plankton Res. 22: 2015-2038.

Nissling, A. 2004. Effects of temperature on egg and larval survival of cod (Gadus morhua) and sprat (Sprattus sprattus) in the Baltic Sea - implications for stock development. Hydrobiologia, 514: 115-123.

Ottersen, G., Hjermann, D.Ø., and Stenseth, N.C. 2006. Changes in spawning stock structure strengthen the link between climate 
and recruitment in a heavily fished cod (Gadus morhua) stock. Fish. Oceanogr. 15: 230-243.

Patokina, F.A., and Feldman, V.N. 1998. Peculiarities of trophic relations between Baltic herring (Clupea harengus membras L.) and sprat in the south eastern Baltic Sea in 1995-1997. ICES CM 1998/CC:7.

Pepin, P. 1991. Effect of temperature and size on development, mortality, and survival rates of the pelagic early life history stages of marine fish. Can. J. Fish. Aquat. Sci. 48: 503-518.

Sinclair, M. 1988. Marine populations: an essay on population regulation and specification. University of Washington Press, Seattle, Wash.

Sissenwine, M.P. 1984. Why do fish populations vary? In Exploitation of marine communities. Edited by R. May. Springer-Verlag, Berlin. pp. 59-94.

Skogen, M.D. 2005. Clupeoid larval growth and plankton production in the Benguela upwelling system. Fish. Oceanogr. 14: 64-70.

Sogard, S.M. 1997. Size-selective mortality in the juvenile stage of teleost fishes: a review. Bull. Mar. Sci. 60: 1129-1157.

Stepputtis, D., Hinrichsen, H.-H., Goetze, E., and Boettcher, U. 2003. How behaviour of clupeid fishes in the Central Baltic Sea depends on physical factors. ICES CM 2003/P:13.

Takahashi, M., and Watanabe, Y. 2005. Effects of temperature and food availability on growth rate during late larval stage of Japa- nese anchovy (Engraulis japonicus) in the Kurushio-Oyashio transition region. Fish. Oceanogr. 14: 223-235.

Takasuka, A., Aoki, I., and Mitani, I. 2004. Three synergistic growth-related mechanisms in the short-term survival of larval Japanese anchovy Engraulis japonicus in Sagami Bay. Mar. Ecol. Prog. Ser. 270: 217-228.

Voss, R., Köster, F.W., and Dickmann, M. 2003. Comparing the feeding habits of co-occurring sprat (Sprattus sprattus) and cod (Gadus morhua) larvae in the Bornholm Basin, Baltic Sea. Fish. Res. 63: 97-111.

Voss, R., Clemmesen, C., Baumann, H., and Hinrichsen, H.-H. 2005. Baltic sprat larvae: coupling food availability, larval condition and survival. Mar. Ecol. Prog. Ser. 308: 243-254.

Wilhelm, M.R., Painting, S.J., Field, J.G., Kerstan, M., and Durholtz, M.D. 2005. Impact of environmental factors on survival of larval and juvenile Cape anchovy Engraulis encrasicolus (G.) in the southern Benguela upwelling region, determined from hatchdate distributions: implications for recruitment. Mar. Freshw. Res. 56: 561-572.

Zeldis, J.R., Oldman, J., Ballara, S.L., and Richards, L.A. 2005. Physical fluxes, pelagic ecosystem structure, and larval fish survival in Hauraki Gulf, New Zealand. Can. J. Fish. Aquat. Sci. 62: $593-610$ 